\title{
Adult tobacco use practice and its correlates in eastern Ethiopia: A cross-sectional study
}

Ayalu Alex Reda ${ }^{1,2^{*}}$, Daniel Kotz ${ }^{3}$ and Sibhatu Biadgilign ${ }^{4}$

\begin{abstract}
Background: There is paucity of data on the smoking habits of rural populations in developing countries. This study aimed to explore cigarette smoking practices of a rural community in Ethiopia.

Methods: A community based cross-sectional study was conducted among 548 individuals from a random sample of households in a rural town and its surrounding rural districts. Descriptive statistics and logistic regression were performed.

Results: Twenty-eight percent (95\% Cl: $24.3 \%-31.6 \%$ ) of the respondents were current smokers. A total of 105 (68\%) smokers expressed an interest to quit while 37 (34\%) had tried to quit previously but without success. There was high exposure to second-hand smoke: 285 (52\%) homes allowed indoor smoking, and in 181 (33\%) indoor smoking took place daily. Current smoking was strongly associated with male sex (OR=83.0; 95\% Cl: $11.5-599.0$ ), and being a student was found to be protective of smoking ( $\mathrm{OR}=0.04 ; 95 \% \mathrm{Cl}: 0.005-0.05)$.

Conclusion: Cigarette smoking is prevalent among the male rural town population in Ethiopia. In addition, a high level of exposure to indoor second-hand smoke exists. There is a need for investment in rural tobacco control, including educational campaigns and cost-effective smoking cessation services.
\end{abstract}

Keywords: Smoking, Tobacco, Cigarettes, Ethiopia, Practice, Attitude, Rural, Population, Correlates

\section{Introduction}

Tobacco use is one of the major preventable causes of premature death and disease in the world [1]. Tobacco use is increasing worldwide because of increased consumption in low-income countries [2-4]. As a result, a disproportionate share of the global tobacco burden falls on developing countries, where $84 \%$ of 1.3 billion current smokers reside [1]. The World Health Organization (WHO) attributes approximately 5 million deaths a year to tobacco. This number is expected to exceed 10 million deaths by 2020 , with approximately $70 \%$ of these deaths occurring in developing countries [5]. Tobacco related deaths currently rank 2nd and 7th in middle-income and low-income countries respectively [6]. In Sub-Saharan Africa smoking caused just 100,000 deaths in 1990 and is projected to lead to deaths of more than 700,000 people in 2015 [7].

\footnotetext{
* Correspondence: ayaluaklilu@yahoo.com

${ }^{1}$ Population Studies and Training Center, Brown University, Providence, RI, USA

${ }^{2}$ Department of Public Health, College of Health Sciences, Haramaya University, P. O. Box 138 Harar, Ethiopia

Full list of author information is available at the end of the article
}

The tobacco epidemic is preventable. It was on this basis that World Health Assembly of the WHO unanimously adopted the Framework Convention on Tobacco Control (FCTC) in May 2003 [8]. This convention aims to tackle the epidemic at both national and global levels through a range of policy interventions. These interventions involve, among others, monitoring of tobacco use prevalence; offer of help for quitting tobacco use; warnings about the dangers of tobacco use; and bans on tobacco promotion and sponsorship [3,9].

National and international monitoring of tobacco use is considered essential for success in the fight against the tobacco epidemic [3]. In Ethiopia, nationally representative data on smoking prevalence and the effects of smoking are non-existent [10]. An earlier study reported an adult prevalence of $15.8 \%$ in 2005 [10], while a World Health Organization (WHO) estimate indicates a national tobacco use prevalence of 7.6\% [3]. Most of these studies on smoking in the country have been conducted in urban populations or specific groups such as students $[11,12]$ while rural areas and towns, where the majority $(84.0 \%)$ of
Ciomed Central

(c) 2013 Reda et al.; licensee BioMed Central Ltd. This is an open access article distributed under the terms of the Creative Commons Attribution License (http://creativecommons.org/licenses/by/2.0), which permits unrestricted use, distribution, and reproduction in any medium, provided the original work is properly cited. 
the population lives [13] are neglected in tobacco research [14]. So, the aim of this study was to assess cigarette smoking practice and its correlates among a rural town population in eastern Ethiopia.

\section{Methods}

Study area and period

A community based cross sectional study was conducted in Kersa town, eastern Ethiopia from February to July 2010. The source population for this study were individuals above the age of 15 years enrolled under the Kersa Demographic Surveillance and Health Research Center (KDS -HRC). The KDS-HRC is located in Kersa district, Oromia region, Ethiopia. It is a demographic and mortality surveillance site intended to monitor mortality and morbidity in the study area. The study site has twelve Kebeles (the smallest administrative unit in Ethiopia) with 10,256 households and a population of 48,192 [15]. Our sample was taken from the rural town of Kersa and the surrounding rural districts which had 3,004 households representing 11,072 persons at the time of the study.

\section{Data collection procedure}

In 1998, the WHO, US Centers for Disease Control and Prevention (CDC), and the Canadian Public Health Association (CPHA) developed the Global Tobacco Surveillance System (GTSS) to assist countries in establishing tobacco use control and prevention programs [5]. One of the survey tools developed by the GTSS is the Global Adult Tobacco Survey (GATS) questionnaire which is aimed to assess smoking among adults. It contains items on smoking and its magnitude, knowledge of the risks of smoking, smoking cessation etc. The GATS questionnaire [16] was translated into Oromifa (the local language) and adopted for data collection through interviews.

In order to avoid sampling of more than one person in the same household and increase representation, we selected households first and then the individual. Sample size was calculated using a single proportion [17] sample size formula with the following assumption: $95 \%$ confidence interval $(\mathrm{CI})$, prevalence of smoking of $25 \%$, margin of error of $2.8 \%$, and a $10 \%$ non-response rate. This gave a sample of 600 individuals. Six hundred households were then randomly sampled using the KDS-HRC digital database as a sampling frame. Data collectors visited the selected households and enumerated members above the age of 15 years. Then one person was selected for interview from this list using the random number generator table included in the standardized GATS questionnaire. The investigators and two site personnel supervised the data collection process. The questionnaire was pretested among 38 individuals taken from a similar population in a nearby district.

\section{Data analysis}

Data were entered and analyzed using $\mathrm{IBM}^{\circ} \mathrm{SPSS}^{\circ}$ Statistics, version 15 for Windows. Descriptive statistics and logistic regression were performed. These included binary as well as multiple logistic regression models where status of smoking was entered as the dependent variable and socio-demographic measurements as independent variable. Proportions and their 95\% confidence intervals were calculated to assess cigarette smoking practice. P-values less than 0.05 were considered significant.

\section{Operational definitions}

The responses to the questionnaire item "Do you currently smoke tobacco?" were used for assessing current smoking, and "Have you smoked tobacco daily in the past?" for former smoking.

\section{Ethical clearance}

Ethical clearance was obtained from the institutional research ethics review (IRB) board of Haramaya University. Verbal informed consent was obtained from respondents.

\section{Results}

Five hundred forty-eight of the 600 respondents responded to interviews, providing a response rate of $91.3 \%$. There were 405 male respondents $(75.1 \%)$ and the mean (SD) age of the respondents was 35.0 (15.0) years (Table 1).

\section{Practice and attitudes toward smoking}

One hundred fifty-one (28\%) respondents reported to smoke daily, whereas $6(1.1 \%)$ smoked on a non-daily basis (1.1\%). The proportion of current smokers (daily and nondaily smoking at the time of the study) was $38.6 \%$ among males and $0.8 \%$ among females. Twenty-two (4\%) of the respondents were former smokers, from which $10(1.8 \%)$ were daily smokers. The mean (SD) age of smoking initiation was 21.1 (6.4) years. Twenty-six (5\%) of the respondents used smokeless tobacco, mainly in the form of chewing. From these 9 (1.7\%) used it daily. The mean (SD) number of cigarettes smoked per week by smokers was 47.2 (51.4), showing a significant variation from 1 to 168 cigarettes. This amounts to an average of 6.7 cigarettes smoked per day (range 24). The mean (SD) expense of the last cigarette purchase was 4.7 (6.1) birr (currency of Ethiopia) which amounts to $\$ 0.9$ (\$1.1) in 2010 purchasing power adjusted dollars.

Thirteen (8.7\%), 21 (14.0\%), 24 (16.0\%), and 92 (61.3\%) smokers reported to smoke the first cigarette within respectively 5, 6-30, 31-60, and more than 60 minutes after waking up in the morning. About $34.0 \%$ (49) of smokers had tried to stop smoking in the past. The mean (SD) number of days of cessation was 5.9 (13.5). A total of nineteen $(27.9 \%)$ smokers who visited a health facility in the 
Table 1 Background and socio-economic characteristics of the sampled population ( $N=548$ )

\begin{tabular}{|c|c|c|c|}
\hline Characteristics & Male & Female & Total \\
\hline Sex & $405(75.1)$ & $134(24.9)$ & 539 \\
\hline Age, mean (SD) & $35.0(13.6)$ & $34.0(18.4)$ & $35.0(15.0)$ \\
\hline \multicolumn{4}{|l|}{ Religion } \\
\hline Christian & $71(17.7)$ & $42(30.9)$ & $115(21.3)$ \\
\hline Muslim & $328(81.8)$ & $92(69.2)$ & $424(78.3)$ \\
\hline Others & $2(0.5)$ & $0(0.0)$ & $2(0.4)$ \\
\hline \multicolumn{4}{|l|}{ Education } \\
\hline Illiterate & $162(40.1)$ & $78(58.2)$ & $243(44.7)$ \\
\hline Below secondary school & $168(41.6)$ & $30(22.4)$ & $200(36.8)$ \\
\hline Secondary school completed & $30(7.4)$ & $14(10.4)$ & $45(8.3)$ \\
\hline High school completed & $23(5.7)$ & $7(5.2)$ & $30(5.5)$ \\
\hline College completed & $16(4.0)$ & $4(3.0)$ & $20(3.7)$ \\
\hline Postgraduate & $4(1.0)$ & $0(0.0)$ & $4(0.7)$ \\
\hline \multicolumn{4}{|l|}{ Marital status } \\
\hline Single & $93(22.4)$ & $102(77.2)$ & $198(28.6)$ \\
\hline Married & $309(76.3)$ & $30(22.4)$ & $343(63.4)$ \\
\hline \multicolumn{4}{|l|}{ Work status } \\
\hline Governmental employee & 55 (13.6) & $11(8.3)$ & $70(12.9)$ \\
\hline Non-governmental employee & $8(2.0)$ & $2(1.5)$ & $10(1.8)$ \\
\hline Self-employed & $279(69.2)$ & 38 (28.8) & 319 (58.9) \\
\hline Student & $46(11.4)$ & 27 (20.5) & 73 (13.5) \\
\hline Homemaker & $3(0.7)$ & 24 (18.2) & $27(5.0)$ \\
\hline Unemployed & $5(1.2)$ & $7(5.3)$ & $12(2.2)$ \\
\hline Other & $7(1.7)$ & $23(17.4)$ & $31(5.7)$ \\
\hline
\end{tabular}

Figures are presented as $\mathrm{N}(\%)$, unless otherwise stated.

past year were asked by health personnel about the use of tobacco and 16 (24.6\%) were advised to quit. The main method used for smoking cessation was counselling (25\%). Regarding plans to quit smoking, 16 (10.3\%), 31 (20.0\%), $58(37.4 \%)$ respondents aimed to quit respectively within 6 months, 12 months, and some day but not within 12 months. Thirty-seven (23.9\%) smokers were not interested in quitting. Plan to quit was negatively associated with number of cigarettes smoked per week $\left(X^{2}=34.3\right.$, $\mathrm{df}=3, \mathrm{p}<0.001)$.

\section{Factors associated with smoking}

In the multivariate analysis using logistic regression current smoking was strongly associated with male sex $(\mathrm{OR}=83.0$; 95\% CI: 11.5-599) and students had lower odds of smoking than those of employed respondents $(\mathrm{OR}=0.04 ; 95 \% \mathrm{CI}: 0.005-0.05)$. Age was statistically significant in the bivariate analysis $(\mathrm{OR}=1.02 ; 95 \% \mathrm{CI}$ : 1.01-1.03) but not after adjustment for other variables (Table 2).
Table 2 Predictors of currents smoking in Kersa town, eastern Ethiopia

\begin{tabular}{lll}
\hline Predictors & Crude OR $\mathbf{( 9 5 \% ~ C l )}$ & Adjusted OR $(\mathbf{9 5} \% \mathbf{C I})^{\mathbf{*}}$ \\
\hline Age & $1.02(1.01-1.03)$ & $1.01(0.99-1.03)$ \\
Religion & & \\
Muslim & $3.3(1.8-5.9)$ & $1.9(0.8-4.6)$ \\
Christian & 1.0 & 1.0
\end{tabular}

Sex

Male $\quad 83.0(11.5-599) \quad 87.6(10.8-708.6)$

Female

1.0

1.0

Education

Illiterate

$3.9(2.8-5.4)$

$2.3(0.9-6.2)$

Below secondary school

$2.0(1.4-2.8)$

$1.4(0.6-3.5)$

Higher

1.0

1.0

Marital status

Married

$4.0(2.5-6.3)$

$1.5(0.8-2.9)$

Single

1.0

1.0

Work status

Employed

1.0

Self-employed

$3.5(2.5-4.8) \quad 1.5(0.6-4.1)$

Student

$0.03(0.01-0.07)$

$0.04(0.005-0.05)$

Unemployed

$1.5(0.7-3.1)$

$0.23(0.025-2.26)$

Others

$0.08(0.03-0.22)$

$1.5(0.2-11.1)$

${ }^{¥}$ Negelekerke $R^{2}=40.3 \%$; Cox \& Snell $R^{2}=28.2 \%$; $-2 L L=446.7$; Hosmer and

Lameshaw test p 0.234; Correct classification $75.1 \%$.

\section{Indoor smoking}

Two hundred ten (40\%) households allowed indoor smoking and sixty-seven (12.2\%) allowed it with exceptions. One hundred sixty-six (31\%) homes never allowed indoor smoking while ninety two (16.9\%) did not have rules on second hand smoke. In one-third of homes (33\%) smoking took place daily. Four hundred (73.0\%) respondents believed that second hand smoking causes health problems. With respect to the health consequences of second hand smoke, heart disease was reported by $81.9 \%$ (357) of the respondents; respiratory problems by $89.7 \%$ (401); and lung cancer by $84.7 \%$ (371).

\section{Discussion}

Our findings indicate that smoking is practiced highly (28.6\%) among the population studied. Being male was a strong predictor of tobacco use. Smokers consumed an average of 6.7 (range 24) cigarettes, where the last purchase cost them an average of $0.9(\mathrm{SD}=1.1)$ dollars. About $68 \%$ of smokers had interest to quit while $34 \%$ had tried to quit previously but without success. There was a high exposure to second-hand smoke; $52 \%$ of homes allowed indoor smoking and in 33\% smoking took place daily.

Compared to findings from other parts of the country $[11,12,18]$, the practice of smoking in this rural population 
is very high. In this study, the prevalence of smoking was $0.2 \%$ among females. Our findings of smoking practice are also more than the $8.1 \%$ and $13.3 \%$ rates of smoking reported among university students and instructors respectively in Northern Ethiopia [11,12]. In fact, the cigarette smoking prevalence in the current study population is much higher than the national average of $7.2 \%$ [3]. Interestingly, it is even higher or comparable to reports from countries such as Kenya 22.9\% [19], Tanzania 21\% [19], and Tunisia 30.4\% [20], where smoking practices are considered higher by African standards [19].

In a similar manner to other reports in Ethiopia and elsewhere, males contribute most to the habit of smoking $[11,12,18,20,21]$. The 2005 Ethiopian Demographic and Health Survey (EDHS) estimated the prevalence of smoking among males aged $15-49$ years at $9 \%$, where as for females it was $2 \%$ [22]. A survey of a rural town population in southern Ethiopia by Schoenmaker and colleagues reported that $5.8 \%$ of the population and $15.4 \%$ of males smoked [18]. In reports from Africa $[14,20,23,24]$ and elsewhere $[2,14,21]$, smoking was independently associated with male sex after adjustment for other variables such as age and occupation. This could be because of the conservative culture prevalent in the study area where females are not allowed to use tobacco and alcohol. In this study, students had lower levels of smoking compared to the rest of the sample. Some studies report higher smoking rates among the unemployed or little educated $[14,21,25]$, others higher education groups $[18,25]$. Compared to other faiths, being a Muslim is commonly reported as a predictor of smoking in studies conducted in other parts of Ethiopia $[11,18]$ and outside [14]. In this study, while it was significant on bivariate analysis its effect diminished on multivariate analysis $(\mathrm{p}=0.11)$.

Even though differences in definitions of tobacco use may contribute to differences between studies, their contribution to very high differences is limited. The primary factor that could explain the high level of tobacco use in this rural population is the fact that khat (Catha edulis), a stimulant leaf composed of the psychoactive chemical methamphetamine, is highly consumed along with tobacco and is extensively farmed $[11,18]$. Khat is consumed in private and at social events by all age groups and both sexes since it is part of the culture of the present population. In the khat chewing ritual, smoking helps to heighten the stimulant effect of khat and to break the negative psychological states such as depression that ensue when the stimulation from the khat subsides.

Not only active smoking but also second-hand smoking is expected to have a high impact on health. In this study population a large percentage of homes (52\%) allowed indoor smoking. This figure is higher than a report from Georgia in the US where only $12 \%$ of homes allowed smoking [26] but lower than the 75\% report from the Dominican Republic [2]. This is a risky situation as rural homes in Ethiopia as elsewhere also grapple with indoor smoke arising from burning biomass fuel [27]. It is reported that children particularly face allergic and respiratory problems as a result of exposure to second hand smoke [28] and is a cause of the underrecognized problem of Chronic Obstructive Pulmonary Disease (COPD) among adults in the developing world. Interestingly, smokers knew more about the impacts of second hand smoke than non-smokers. This may explain the high rate of lenience by households toward smoking at home in this study as non-smokers may underestimate the risks involved and fail to take prohibitive action. For instance, a study in the US indicated that among respondents who are smokers and live with children, $85 \%$ reported that smoking occurs regularly in their homes [29].

Smokers in this study seem to smoke fewer cigarettes per day $($ mean $=6.7)$ in comparison to reports from other countries $[18,20,30]$ such as Tunisia where a mean consumption of 17.7 cigarettes per day was reported [20]. A different report from a rural town in southern Ethiopia indicated a similar cigarette consumption pattern to this study, where respondents smoked a mean of 6.6 cigarettes per day [18]. Reports among students and university instructors in Northern Ethiopia indicated a consumption rate of 3.2 and 8.6 cigarettes per day respectively. It is also acknowledged that dissimilarity in the definition of smoking/tobacco use may explain the apparent difference in consumption patterns and quit attempts.

The smokers in this study spent an average of 0.9 dollars on cigarettes in their last purchase. This is a large sum in a country where nearly one third of the population lives below the poverty line (an income of $\leq \$ 1.25$ per day) [31]. It is reported that low socio-economic tobacco users tend to use more and spend a significant share of their income on tobacco compared to wealthy individuals $[2,3,14,21,32]$. This leads not only to diversion of personal and household income [32], but also to a greater level of suffering for both users and their families as second-hand smokers [28]. This becomes a serious burden to poor countries as they have to also grapple with the consequences of tobacco use on top of their traditional infectious disease challenge $[4,6,33]$. Smoking may ultimately lead to death of the bread winner and cut off livelihood of the family since in rural and poor families ability for mobility and physical work is the main form of income [33].

A positive finding of this study is the high interest shown by smokers towards quitting. About 68\% of smokers reported an interest to quit. This is higher than the $57 \%$ proportion reported from a nearby city, Dire Dawa, Ethiopia [34]. For instance, a study from Tunisia indicated that only $9.4 \%$ of the smokers had made a quit 
attempt in comparison to $34 \%$ in this study and a $59.9 \%$ reported from a nearby city [34]. Only $24.5 \%$ of the smokers that went to a health facility were advised to quit smoking. Given the high level of interest to quit by respondents, we believe the opportunity of smoking cessation interventions in the health facilities is underutilized. However, even when assuming a willingness to assist smokers to quit, it is our view that the necessary skills and medications are unavailable.

This study could be a good addition to the literature on smoking in resource poor and rural settings. The strengths of this study are the use of the Global Adult Tobacco Survey (GATS) questionnaire, a standardized international questionnaire with carefully chosen questions to assess tobacco use and also enable comparison of data across settings; and use of representative sample drawn from a sampling frame. The potential limitation of the study is the possibility of response bias especially among female respondents. Given the conservative cultural environment of the country, they may be less encouraged to reveal their substance abuse habits. This is more so when they are requested for such information through face-to-face interviews. However, given the low literacy level in the study population, self-administered questionnaires are not feasible and we were left with interviews as the only means of data collection.

In conclusion, there was a high practice of consumption of cigarettes among males in the study population. The prevalence of smoking among females was very minimal. There was a high level of indoor air pollution from second hand smoke. The majority of smokers were interested in quitting smoking. Concerted effort is required from community leaders, health workers, and policy makers to avert the existing tobacco use and its consequences. Specifically, there is a need for investment in tobacco control, including educational campaigns and development of costeffective smoking cessation services such as counselling in smokers presenting at health care institutions in the study area.

\section{Competing interests}

All authors declare that they have no conflict of interest associated with the publication of this manuscript.

\section{Authors' contributions}

AAR conceived and designed the study and collected data in the field, performed analysis, wrote a draft of the manuscript. DK assisted with the design, interpretation of data and the critical review of the manuscript. SB performed interpretation of data, and critically reviewed the manuscript. All authors approved and read the final manuscript. All authors participated in critical appraisal and revision of the manuscript.

\section{Acknowledgement}

We would like to express our gratitude to the Kersa Demographic and Health Surveillance Centre and its staff. Funding for this study was obtained from Haramaya University.

\section{Author details}

${ }^{1}$ Population Studies and Training Center, Brown University, Providence, RI, USA. ${ }^{2}$ Department of Public Health, College of Health Sciences, Haramaya University, P. O. Box 138 Harar, Ethiopia. ${ }^{3}$ CAPHRI School for Public Health and Primary Care, Maastricht University Medical Centre, Maastricht, the Netherlands. ${ }^{4}$ Department of Epidemiology and Biostatistics, College of Public Health and Medical Sciences, Jimma University, Jimma, Ethiopia.

Received: 27 August 2011 Accepted: 27 October 2013

Published: 31 October 2013

\section{References}

1. Jha P, Chaloupka FJ: Tobacco control in developing countries. Oxford, UK: Oxford University Press; 2000

2. Ossip-klein, Fisher S, Diaz S, Quinones Z, Sierra E, Dozier A, Mcintosh S, Guido J, Winters P, Diaz O, Armstrognt L-T: Tobacco use in six economically disadvantaged communities in the Dominical Republic. Nicotine Tob Res 2008, 10:851-860.

3. WHO: Report on global tobacco epidemic. 2008.

4. Slama K: Global perspective on tobacco control. Part I. The global state of the tobacco epidemic. Int J Tuberculosis Lung Dis 2008, 12:3-7.

5. Warren CW, Jones NR, Peruga A, Chauvin J, Baptiste J-P, de Silva VC, el Awa F, Tsouros A, Rahman K, Fishburn B, et al: Global youth tobacco surveillance, 2000-2007. MMWR 2008, 57:1-21.

6. Venkat Narayan KM, Ali MK, Koplan JP: Global non communicable diseases where worlds meet. N Engl J Med 2010, 363:1196-1198.

7. Murray $C J$, Lopez AD: Alternative projections of mortality and disability by cause 1990-2020: Global Burden of Disease Study. Lancet 1997, 349:1498-1504.

8. WHO Framework Convention on Tobacco Control: development of an evidence based global public health treaty. BMJ 2003, 327:154-157.

9. Fong GT, Cummings KM, Borland R, Hastings G, Hyland A, Giovino GA Hammond D, Thompson ME: The conceptual framework of the International Tobacco Control (ITC) Policy Evaluation Project. Tob Control 2006, 15:iii3-iii11.

10. Melaku K, Aderaye G: Chronic respiratory diseases in Ethiopia. In Epidemiology and Ecology of Health and Disease in Ethiopia. Edited by Berhane Y, Haile-Mariam D, Kloos H. Addis Ababa, Ethiopia; 2005.

11. Kebede $Y$ : Cigarette smoking and Khat chewing among college students in North West Ethiopia. Ethiop J Health Dev 2002, 16:9-17.

12. Kebede $Y$ : Cigarette smoking and khat chewing among university instructors in Ethiopia. East Afr Med J 2002, 79:274-278.

13. CSA: Summary and statistical report of the 2007 population and housing census results. Addis Ababa, Ethiopia: Central Statistical Authority of Ethiopia; 2008

14. Rani M, Bonu S, Jha P, Nguyen SN, Jamjoum L: Tobacco use in India: prevalence and predictors of smoking and chewing in a national cross sectional household survey. Tob Control 2003, 12:e4

15. Assefa N, Berhane Y, Worku A: Predictors of Unintended Pregnancy in Kersa, Eastern Ethiopia, 2010. Reprod Health 2012, 9.

16. Global Tobacco Surveillance System (GTSS), Global Adult Tobacco Survey (GATS): Core questionnaire with Optional Questions. 2008. World Health Organization (WHO)

17. Kelsey JL, Whittemore AS, Evans AS, Thompson WD: Methods of sampling and estimation of sample size. In Methods in observational epidemiology. 2nd edition. Edited by Kelsey JL WA, Evans AS, Thompson WD. New York and Oxford: Oxford University Press; 1996:311-340.

18. Schoenmaker N, Hermanides J, Davey G: Prevalence and predictors of smoking in Butajira town, Ethiopia. Ethiop J Health Dev 2005, 19:182-187.

19. Pampel F: Tobacco use in sub-Sahara Africa: Estimates from the demographic health surveys. Soc Sci Med 2008, 66:1772-1783.

20. Fakhfakh R, Hsairi M, Maalej M, Achour N, Nacef T: Tobacco use in Tunisia: behavior and awareness. Bull World Health Organ 2002, 80:350-356.

21. Alam AY, labal A, Mohammad KB, Laporte RE, Ahmed A, Nishtar S: Investigating socio-economic-demographic determinants of tobacco use in Rawalpindi, Pakistan. BMC Public Health 2008, 8

22. Macro CSAoEaO: Ethiopia Demographic and Health Survey. Addis Ababa, Ethiopia and Calverton, Maryland, USA: ORC Macro, and Central Statistical Authority of Ethiopia; 2005

23. Jagoe K, Edwards R, Mugusi F, Whiting D, Unwin N: Tobacco smoking in Tanzania, East Africa: population based smoking prevalence using 
expired alveolar carbon monoxide validation tool. Tob Control 2002, 11:210-214.

24. Walraven GE, Nyan OA, Van Der Sande MA, Banya WA, Ceesay SM, Milligan PJ, McAdam KP: Asthma, smoking and chronic cough in rural and urban adult communities in The Gambia. Clin Exp Allergy 2001, 31:1679-1685.

25. Storr L, Cheng H, Alonso J, Angermeyer M, Bruffaerts R, de Girolamo G, de Graaf R, Gureje O, Karam EG, Kostyuchenko S, et al: Smoking estimates from around the world: data from the first 17 participating countries in the World Mental Health Survey Consortium. Tob Control 2010, 19:65-74.

26. Escoffery $C$, Kegler MC, Butler S: Formative research on creating smokefree homes in rural communities. Health Educ Res 2009, 24:76-86.

27. Edelstein M, Pitchforth E, Asres G, Silverman M, Kulkarni N: Awareness of health effects of cooking smoke among women in the Gondar Region of Ethiopia: a pilot survey. BMC Int Health Hum Rights 2008, 8

28. Law MR, Hackshaw AK: Environmental tobacco smoke. Br Med Bull 1996, 52:22-34.

29. Schuster M, Frank T, Pham CB: Smoking patterns of household members and visitors in homes with children in the United States. Arch Pediatr Adolesc Med 2002, 156:1094-1100.

30. Obot IS: The use of tobacco products among Nigerian adults: a general populaiton survey. Drug Alcohol Dependency 1990, 26:203-208.

31. UNDP: The real wealth of nations: Pathways to human development. In Human development report 2010. 20th edition. 2010.

32. Djibuti M, Gotsadze G, Mataraze G, Zoidze A: Influence of household demographic and socio-economic factors on household expenditure on tobacco in six New Independent States. BMC Public Health 2007, 7.

33. de Beyer J, Lovelace C, Yurkli A: Poverty and tobacco. Tob Control 2001, 10:210-211.

34. Girma E, Tsion A, Deribew A: Cigarette smoker's intention to quit smoking in Dire Dawa town Ethiopia: an assessment using the Transtheoretical Model. BMC Public Health 2010, 10.

doi:10.1186/1477-7517-10-28

Cite this article as: Reda et al:: Adult tobacco use practice and its correlates in eastern Ethiopia: A cross-sectional study. Harm Reduction Journal 2013 10:28.

\section{Submit your next manuscript to BioMed Central and take full advantage of:}

- Convenient online submission

- Thorough peer review

- No space constraints or color figure charges

- Immediate publication on acceptance

- Inclusion in PubMed, CAS, Scopus and Google Scholar

- Research which is freely available for redistribution 